\title{
The Characteristics and Trends of the development of Chinese Freight Transport at the Background of New Normal
}

\author{
LI YanHong, a ,WANG XianGuang ${ }^{2, b}$, and YANG Dong ${ }^{3, c}$ \\ ${ }^{1}$ China Academy of Transportation Sciences/Comprehensive transport research center, Beijing, \\ China \\ ${ }^{2}$ China Academy of Transportation Sciences/Comprehensive transport research center, Beijing, \\ China \\ ${ }^{3}$ China Academy of Transportation Sciences/Comprehensive transport research center, Beijing, \\ China \\ a280773087@qq.com, ${ }^{\text {b } 7731929 @ q q . c o m},{ }^{c}$ 16793315@qq.com
}

Keywords: New Normal; freight transport; freight volume and turnover; freight structure; characteristics; trends.

\begin{abstract}
Chinese economic development has arrived into the fast lane after the reform, The growth rate has changed from high to medium high. The economic structure has been optimized and upgraded. And the growth pattern has transferred from investment-driven to innovation-driven. This paper, from the perspective of freight transport, studied its trends and characteristics, in order to provide theoretical and technical support for the supply-side reform and scientific decision-making regarding transportation sector in China.
\end{abstract}

\section{Introduction}

Chinese economic development has arrived into the fast lane after the reform, which has been experiencing sustained and rapid growth. Since 2012, the growth rate of GDP, however, started to fall back. The growth rate from year 2012 to 2015 respectively reached 7.7\%, 7.7\%, 7.3\% and 6.9\%. The economic finally farewell to the rapid growth during the past 30 years, in which has an average growth rate of $10 \%$, and stepped in to the stage of New Normal. The new stage has three essential characteristics. The growth rate has changed from high to medium high. The economic structure has been optimized and upgraded. And the growth pattern has transferred from investment-driven to innovation-driven. As one of the fundamental, pilot, and service oriented industry for the national economy, the transportation sector must be influenced by the New Normal transition. This paper, from the perspective of freight transport, studied its trends and characteristics, in order to provide theoretical and technical support for the supply-side reform and scientific decision-making regarding transportation sector in China.

\section{The characteristics and rules of Chinese freight transport Introduction}

The characteristics and rules of the freight transport development could be indicated by the variation of relating indicators, mainly including freight volume, freight turnover and freight structure by all kinds of transportation modes. The key is to consider the variation of the absolute value and the growth rate.

A. Freight volume and freight turnover

1) The freight volume increases every year. The growth rate shows a cyclic fluctuation, reaching its peak in 2011 and decreasing gradually in recent 3 years 
In view of the absolute value, the freight volume in China increases gradually each year, which increased 2.3 times, from 12.349 billion tonnage in 1995 to 43.811 billion tonnage in 2015. The freight volume of all kinds of transportation modes all show an increasing trend.

In view of the growth rate, it shows a cyclic fluctuation as well, which raised from 1997 and reached its peak in 2011. While it shows a decreasing trend in recent 3 years.

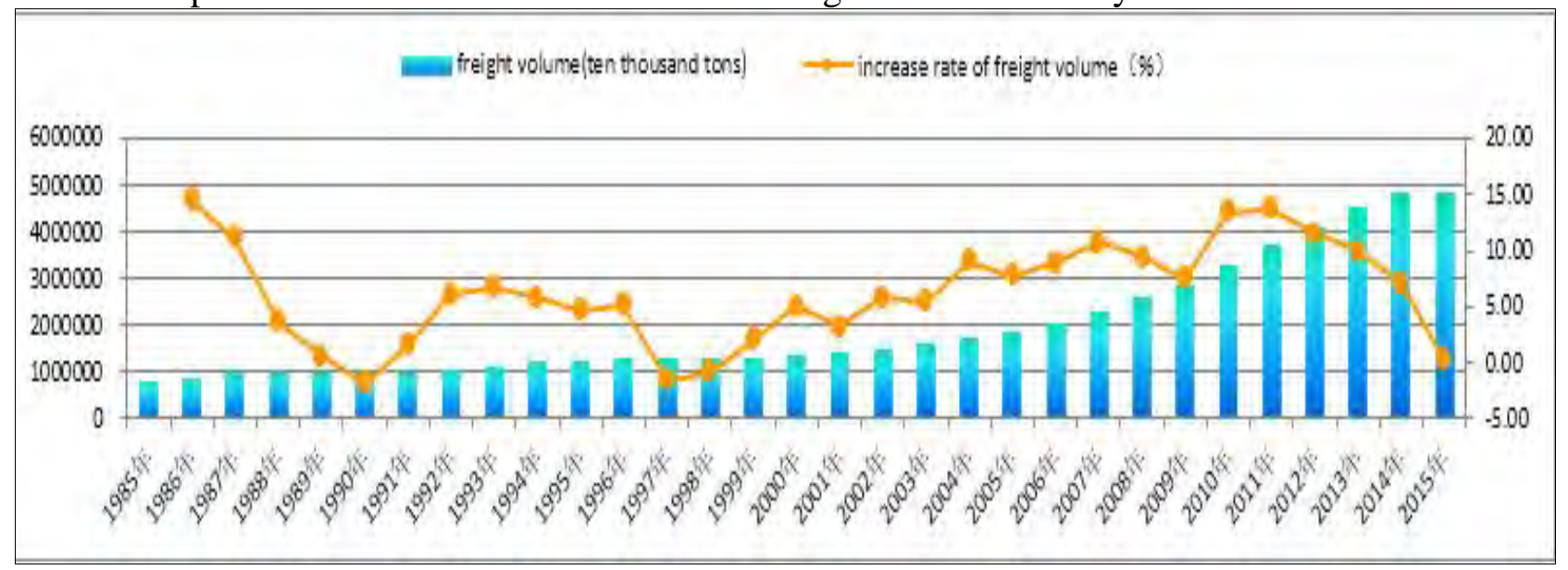

Fig.1 The variation of freight volume and its growth rate in China from 1985 to 2015

2) The freight turnover shows a gradually increasing trend (except in 1998), which increased 8.6 times in 30 years. The growth rate also shows a cyclic fluctuation, and currently at a transition stage from rapid increment to medium or low speed increment

In view of the absolute value, the freight turnover in China increases gradually each year (except the year 1998 influenced by the flood), which increased 8.6 times, from 1836.5 billion ton kilometers in 1985 to 17740.07 billion ton kilometers in 2015.

In view of the growth rate, it shows a cyclic fluctuation as well. In recent 30 years, the growth rate reached its peak during the ten years from the 10th five-year to the 11th five-year, which was at a stage of rapid growth. After arriving into the 12th five-year, the growth rate has been decreasing, and currently at a transition stage from rapid increment to medium or low speed increment.

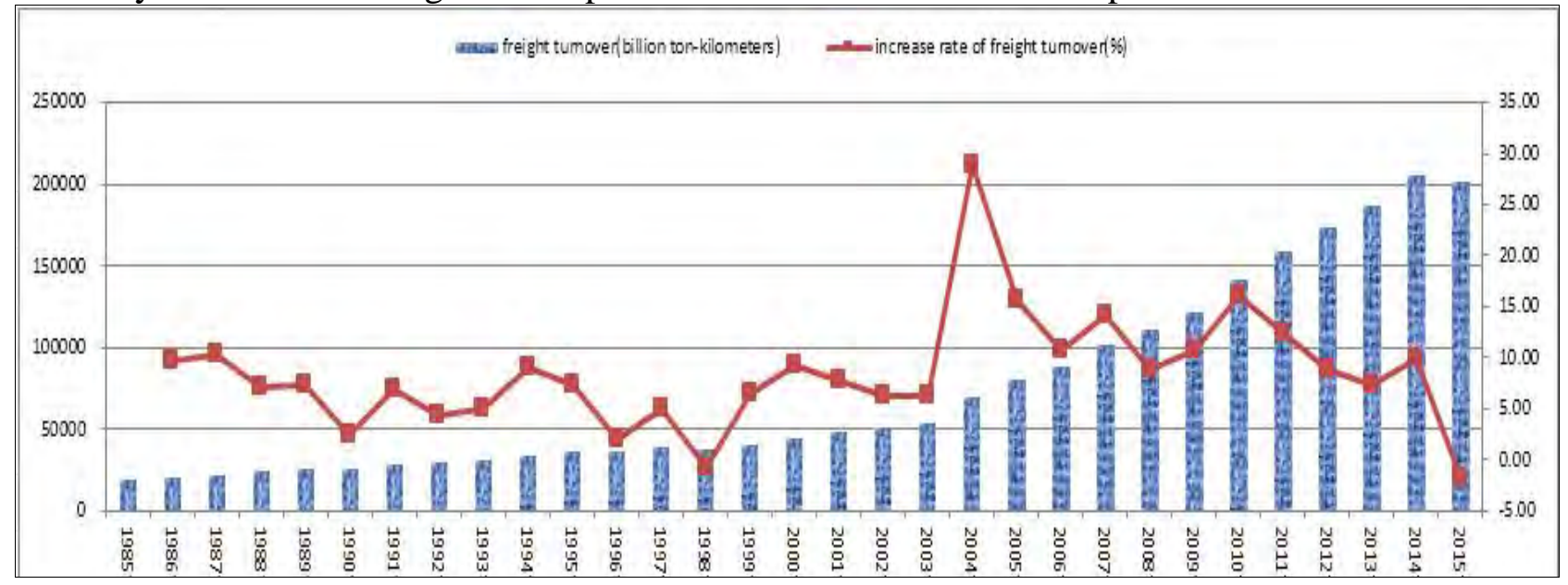

Fig.2 The variation of freight turnover and its growth rate in China from 1985 to 2015

\section{B. Freight structure}

1) Freight volume structure: Railway, highway and waterway transport are the main transportation modes in China, among which highway takes the dominate place, carrying nearly 3/4 of all the freight. While railway and waterway accounts for respectively $10 \%$.

Railway freight volume accounts for a large percentage in the total volume. The average percentage is around $11 \%$ in recent 10 years. Generally, it shows a descending trend. 
Highway freight volume accounts for the majority of all, reaching around $75 \%$. Generally, it shows a slowly rising and stable trend.

Waterway freight volume accounts for around $11 \%$ of the total volume, which is close to that of the railway. From the data in recent 10 years, it shows a trend of being stable.

Air freight volume accounts for the least of all. The percentage is only about $0.01 \%$.

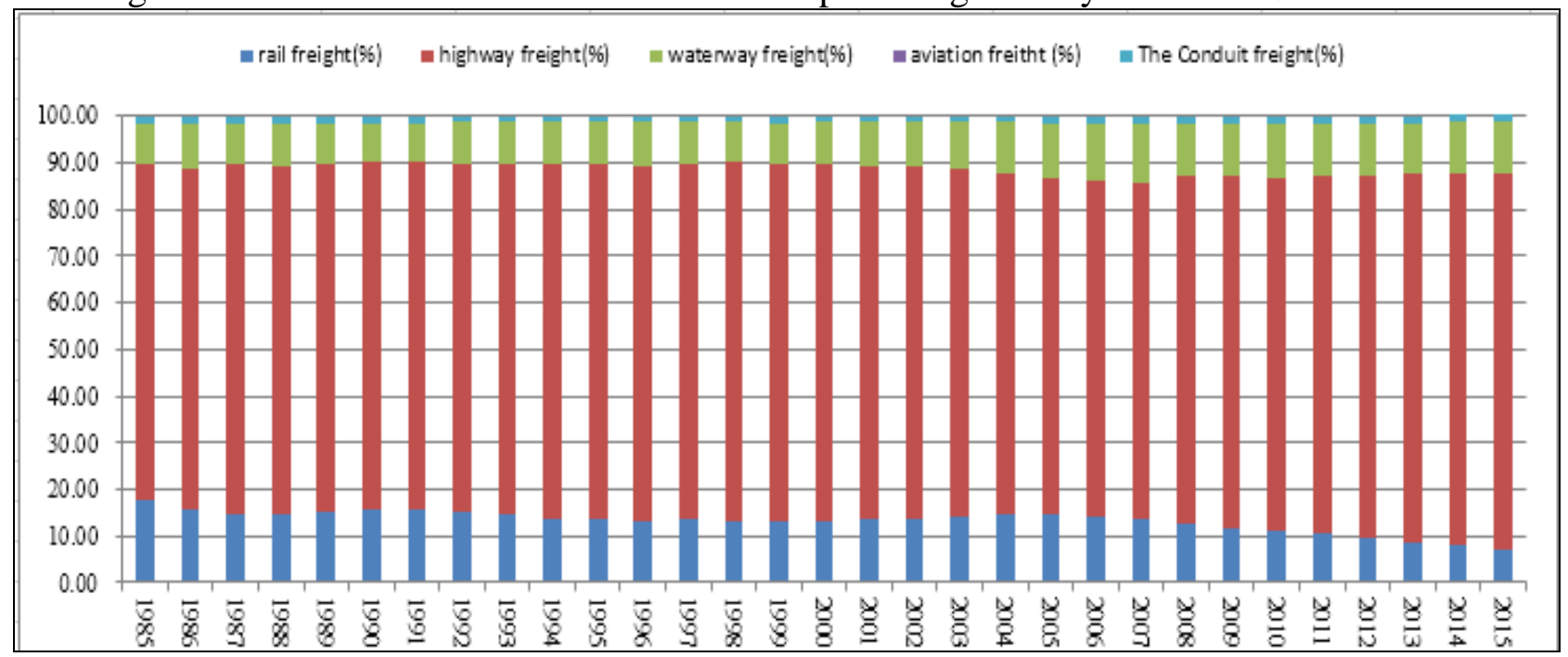

Fig.3 The variation of the percentage of freight volume by all kinds of transportation modes in China from 1985 to 2015

2) Freight turnover structure: Railway, highway and waterway transport are the main transportation modes in China. Waterway transport including marine transport accounts for around $1 / 2$, railway accounts for $30 \%$ and highway accounts for $20 \%$. While when waterway transport is considered without marine transport, highway would account for $1 / 2$, waterway accounts for $30 \%$ and railway accounts for $20 \%$.

Railway freight turnover accounts for a large percentage. The average percentage is around 32\% in recent 30 years. Generally, it shows a gradually descending trend.

Highway freight turnover accounts for around 17\% of all. From the data in recent few years, it shows a slowly rising and stable trend.

Waterway freight turnover accounts for the majority of all, reaching $50 \%$. Generally, it also shows a slowly rising and stable trend.

Air freight volume accounts for the least of all. The percentage is only about $0.08 \%$.

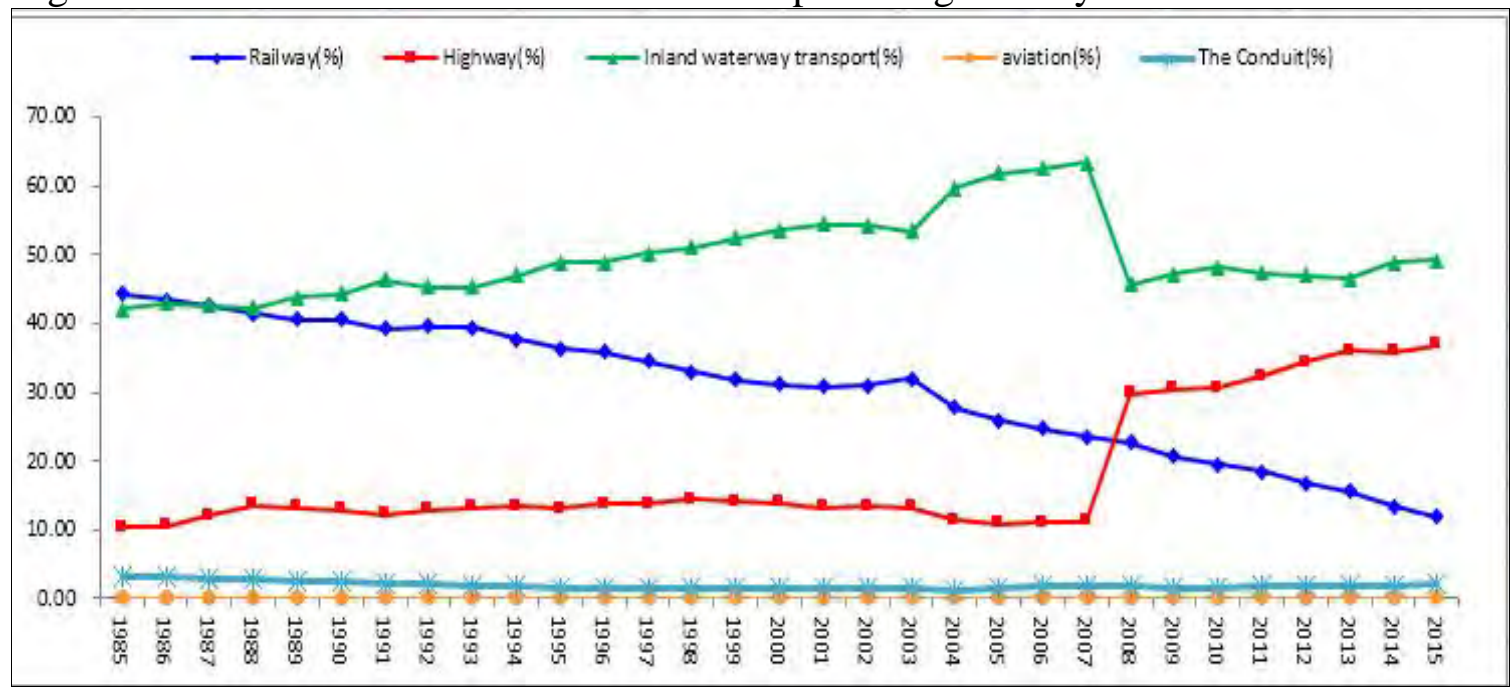

Fig.4 The variation of the percentage of freight turnover by all kinds of transportation modes in China from 1985 to 2015 
3) Freight volume and freight turnover by all kinds of transportation modes.

Railway and waterway freight volume shows a falling trend. Along with the arrival of the post-industrial era, the added value of the second industry achieved the peak value in 2006, and then dropped gradually. The descending of the percentage of heavy chemical industry result in the steady trend of the growth rate of freight volume, especially the bulky cargo volume carried by railway and waterway arterial. After 2013, the railway freight volume appeared to have negative growth.

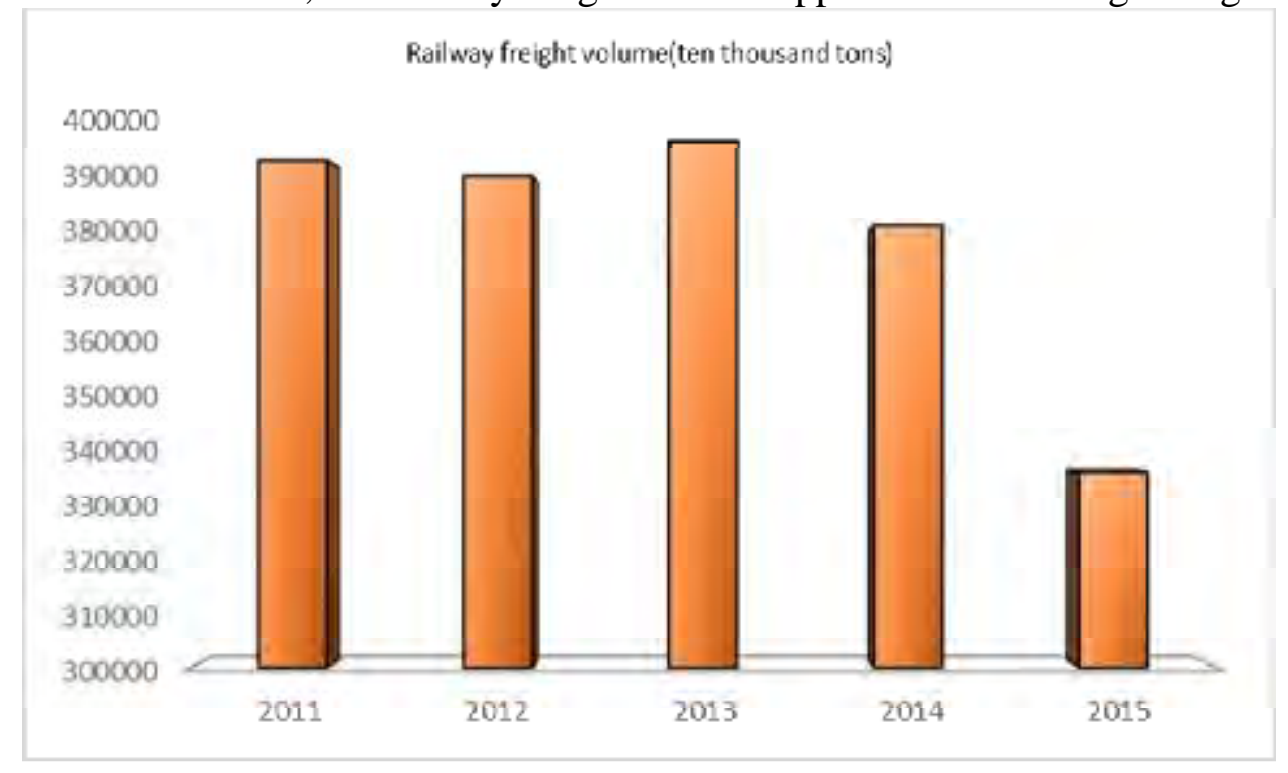

Fig.5 The trend of Chinese railway freight volume during the 12th five-year

Highway freight volume has been experiencing sustainable growth. In recent years, along with the in-depth implementation of regional coordinated development strategy, the industrial distribution among different regions has been optimized, especially in the middle and west regions, which has been carrying on industry transfer, using industry to promote the city development. It caused the demand descending of long distance transport of raw materials and commodities. On the contrary, the demand of middle and short distance transport such as rural and urban logistics increases rapidly. Considering middle and short distance transport belongs to the suitable economical scope of highway transport, the highway freight volume has been experiencing sustainable growth in recent years, the annual average growth rate of which during the 12th five-year reached as high as $8 \%$.

Freight structure varies obviously in different kinds of transportation modes. As the main transportation modes in Chinese domestic arterial freight transport, the freight structure of railway, waterway and highway transport varies greatly. In railway transport, more than $85 \%$ of the freight are bulky cargo, in which coal and coal products, with low value and heavy weight, accounts for more than half. In waterway transport (inland and marine), more than 73\% of the freight are bulky cargo, in which mineral building materials, cement, and wood account for more than $30 \%$. In highway transport, bulky cargo only accounts for $42 \%$. In addition, electromechanical, chemical and light industrial products and medicine account for more than $30 \%$, which lead to the unit price of highway transport. Roughly estimated, it is 5 to 6 times higher than the unit price of railway transport.

\section{Freight structure varies obviously in different kinds of transportation modes.}

As the main transportation modes in Chinese domestic arterial freight transport, the freight structure of railway, waterway and highway transport varies greatly. In railway transport, more than $85 \%$ of the freight are bulky cargo, in which coal and coal products, with low value and heavy weight, accounts for more than half. In waterway transport (inland and marine), more than $73 \%$ of the freight are bulky cargo, in which mineral building materials, cement, and wood account for more than $30 \%$. In highway transport, bulky cargo only accounts for $42 \%$. In addition, electromechanical, chemical and light industrial products and medicine account for more than $30 \%$, which lead to the unit price of highway transport. Roughly estimated, it is 5 to 6 times higher than the unit price of railway transport. 
Table.1 Freight structure of Chinese domestic arterial freight transport (unit: \%)

\begin{tabular}{|l|l|l|l|}
\hline Cargo category & $\begin{array}{l}\text { Railway } \\
\text { transport }\end{array}$ & $\begin{array}{l}\text { Highway } \\
\text { transport }\end{array}$ & $\begin{array}{l}\text { Inland and marine } \\
\text { transport }\end{array}$ \\
\hline Coal and coal products & 62.90 & 7.36 & 23.63 \\
\hline Steel, nonferrous metal, and mineral & 18.04 & 16.53 & 18.32 \\
\hline Mineral building materials, cement, and wood & 4.80 & 18.60 & 31.47 \\
\hline $\begin{array}{l}\text { Grain, agriculture, forestry, animal and fishery products, } \\
\text { chemical fertilizer and pesticide }\end{array}$ & 4.67 & 15.55 & 2.54 \\
\hline $\begin{array}{l}\text { Electromechanical, chemical and light industrial products } \\
\text { and medicine }\end{array}$ & 2.00 & 31.32 & 3.44 \\
\hline Petroleum, gas and its products & 3.64 & 4.15 & 4.43 \\
\hline Others & 3.95 & 6.49 & 16.17 \\
\hline Total & 100.00 & 100.00 & 100.00 \\
\hline
\end{tabular}

\section{Trend of Chinese freight transport development at the background of New Normal}

\section{A. Analysis of essential factors affecting freight transport development.}

1) GDP and its growth rate.

Nowadays, global economy are at a stage of in-depth adjustment. China is facing a more complex international and domestic environment during the modernization. The growth trend prediction of China long-term economy by different institutions are shown in table 2 . Although the specific figures are different, the growth trend of Chinese GDP is the same, and the growth rate is gradually decreasing. Generally, the growth rate from 2016 to 2020 is between 6\% and 7\%, while the growth rate from 2021 to 2030 is between $5 \%$ and $6 \%$.

Table.2 The growth trend prediction of China long-term economy by different institutions

\begin{tabular}{|c|c|c|c|c|c|}
\hline & $\begin{array}{c}\text { Development } \\
\text { Research Center } \\
\text { Year the State } \\
\text { Council }\end{array}$ & $\begin{array}{c}\text { State Information } \\
\text { Center }\end{array}$ & $\begin{array}{c}\text { Research } \\
\text { Chinese } \\
\text { Academy of } \\
\text { Social Sciences }\end{array}$ & $\begin{array}{c}\text { Institute of } \\
\text { Quantitative } \\
\text { Economics and } \\
\text { Technical }\end{array}$ & Research Society \\
& China Energy \\
\hline $2016 \sim 2020$ & $5.5 \sim 6.6$ & 7.2 & 6.4 & 7.3 & 7.3 \\
\hline $2021 \sim 2030$ & 5.4 & 4.7 & 5.4 & 5.5 & 5.5 \\
\hline
\end{tabular}

2) Percentage of the second industry.

In 2006, the percentage of Chinese second industry reached at the peak value of $47.9 \%$, and then began to drop step by step. In 2015, the proportion of Chinese three industries structure is 9.0: 40.5: 50.5. By prediction, the percentage of the added value of Chinese second industry would fall back to $38 \%$ in $2020,35 \%$ in 2030 , and then tend to be steady.

3) Urbanization rate.

A new type of urbanization is the strong power in promoting economic growth, and is also the important source of generating passenger and freight volume. Urbanization rate is a commonly-used indicator to reflect the level of urbanization, which indicates the proportion of urban population in total population (including peasant laborers living in the city over half a year). In 2015, the urbanization rate in China is $56.10 \%$. The urbanization process is boosting and the urbanization level is approximately as the global average level. Based on the prediction by related institution, China 
would be at the middle stage of the acceleration of urbanization during the 13th five-year. The urbanization rate would reach around $60 \%$ in 2020, and the growth rate before 2020 would between $2.0 \%$ and $2.5 \%$. Around 2030 , the urbanization rate would reach $65 \%$ to $70 \%$, and then tend to be steady.

\section{B. Developing trend of freight volume and freight turnover.}

During the future period of time till 2030, the freight volume and freight turnover both would present a trend of gradually increment. However, the growth rate would fall back further, and the freight volume and freight turnover would expectedly achieve or approach the peak value between 2025 and 2030. Comprehensively considering the essential factors affecting freight transport such as economic development (GDP), industrial development especially the second industry, bulky cargo demands, etc., the overall trend of freight turnover development varies along with the development of economic growth and industrial structure changes. During the period of economic prosperity, the market is active, the consumption increases, and the production expanses, accordingly the freight transport demand would be strong. While when the economic trend became smooth or even descending, the circumstances would be on the contrary, and the freight transport demand would be inhibited. By preliminary judgment, during the future period of time till 2030, the freight volume and freight turnover both would present a trend of gradually increment. However, the growth rate would fall back further, and the freight volume and freight turnover would expectedly achieve or approach the peak value between 2025 and 2030. The developing trend is shown in figure 6 and 7.

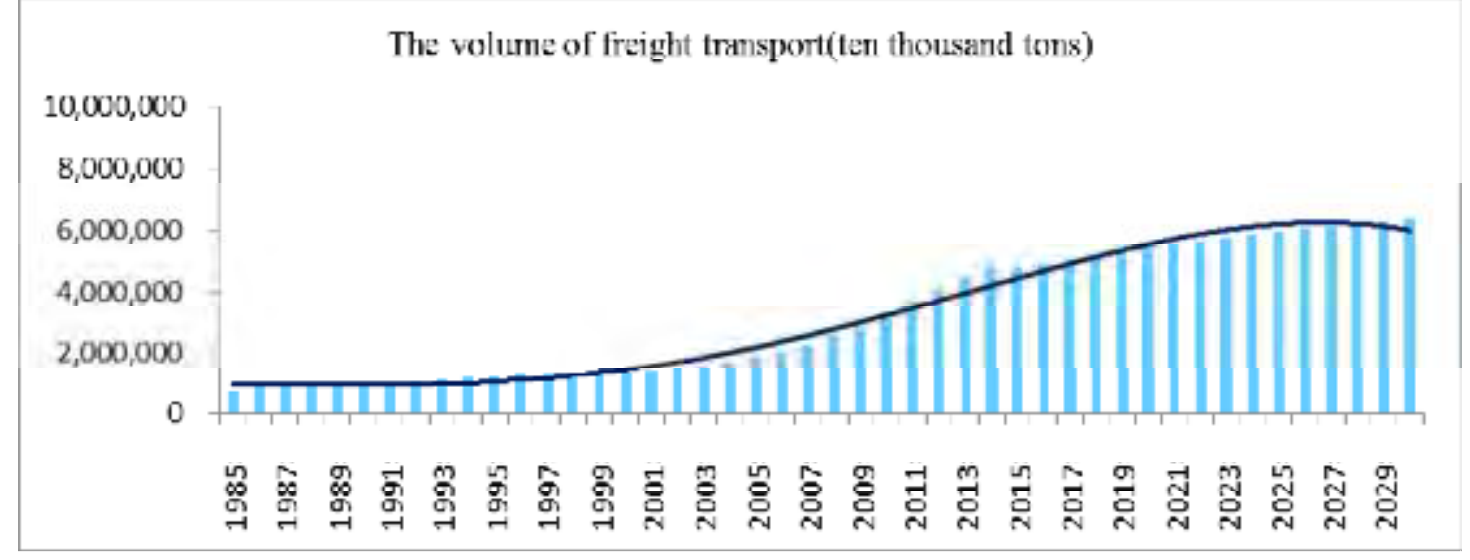

Fig.6 The developing trend of freight volume in China at the background of New Normal

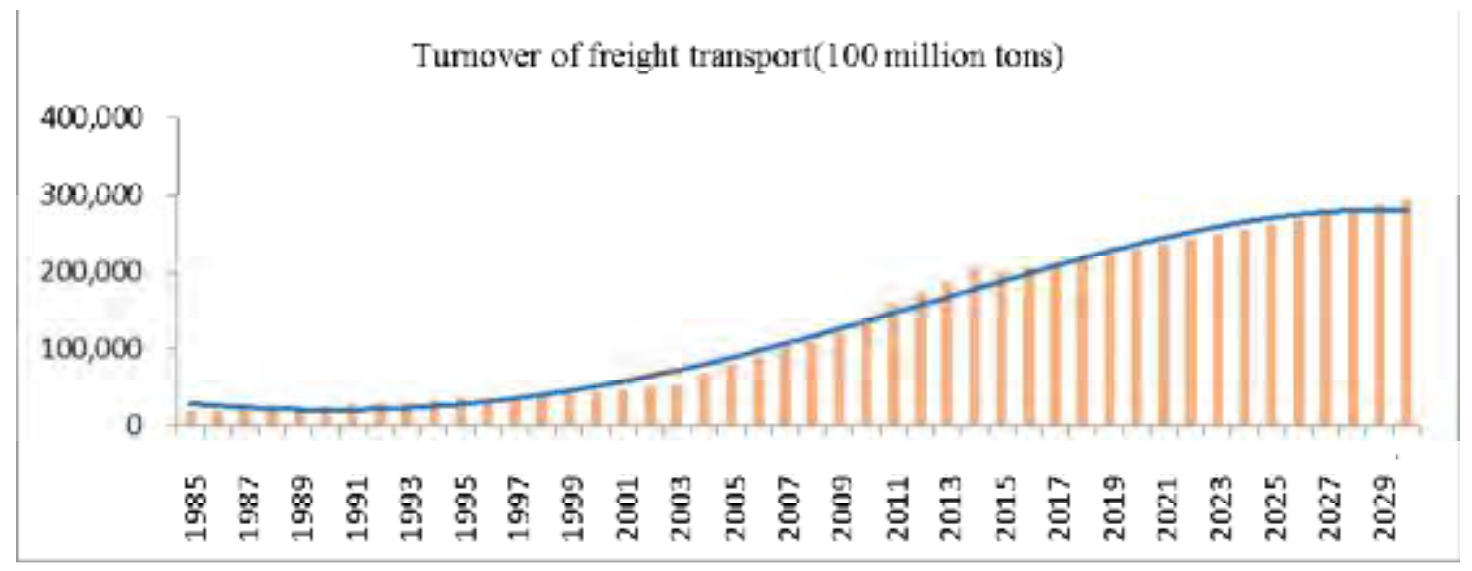

Fig.7 The developing trend of freight turnover in China at the background of New Normal

\section{Developing trend of freight structure.}

Highway, waterway and railway will still be the main transportation modes in Chinese freight transport. The essential reason for highway is that the express delivery industry will remain rapidly developing. By taking advantage of "door to door", highway transport will play a fundamental role in 
rural and urban logistics. The essential reason for waterway is that the advantage of green and energy saving of waterway transport will be more prominent along with the constraint of resources and environment. Railway will be significant for medium and long distance transport. With the formation of reasonable relationships among all kinds of transportation modes in the new era, freight are mainly carried by highway, railway and waterway. And they form a relatively steady freight volume structure. The percentage of railway, highway, waterway and other modes of transportation respectively are around 5\%, 80\%, $10 \%$ and $5 \%$.

D. New characteristics and trends of freight transport.

1) The percentage of light weighted and high added value cargo increases and the demand of express delivery grows largely

The adjustment and upgrade of the industry structure of "Made in China 2015" will lead to the change of transport demand structure. In the future, the percentage of heavy chemistry products would gradually decrease, while the percentage of common consumptions, light weighted and high added value cargo would improve constantly. In addition, the industry will have higher level of requirements to provide safer, timelier and quicker transport service. In the meantime, the demand of express delivery would increase to a large extend with the upgrade of consumption and the development of e-commerce.

Express delivery industry will remain rapid development driven by the e-commerce, basically considering the following points. The first one is that, with the normalization of e-commerce market gradually, B2C will further expand its market share, increasing from currently around $50 \%$ to $70 \%$ in 2010 by an annual average growth rate of 30\%. The second one is that online shopping is combining more closely to the daily life. The mobile e-commerce first surplus PC e-commerce in 2015, accounting for $55 \%$ of the retail share. And the percentage would be expected to be $70 \%$ in 2020 . The third one is that the cross-border e-commerce developed rapidly, which made "international shopping" come true. The compound annual growth rate is predicted to be $30 \%$, and the total amount is expected to reach 1 trillion in 2020. As a result, the express delivery industry will be the future new engine to promote the development of freight transport at the background of Chinese economic New Normal.

2) From the perspective of freight organization, intermodal transport will further improve Future freight transport development proposed new requirement for transportation service quality and integrated transportation hubs. High-level and efficient intermodal transport will be improved such as rail-water, rail-pipeline, and river-marine transport, which requires efficient connection in all kinds of transport links and improving the standardization and transportation equipment, in order to enhance the level of service and transport efficiency.

\section{Strategy and suggestion coping with the new trends of freight transport development}

From the perspective of the demand of freight transport and its growth rate. The demand will remain strong at the background of New Normal, only the growth rate slowing down. Thus, the demand of transportation infrastructure and equipment remains large. The scale of transportation infrastructure will be further expanded, in order to satisfy the increasing needs of freight transport. Meanwhile the equipment should be more professional and high-end oriented to satisfy the needs of efficient transport development.

From the perspective of transportation mode organization, high-level and efficient intermodal transport will be improved such as rail-water, rail-pipeline, and river-marine transport, which requires efficient connection in all kinds of transport links and improving the standardization and transportation equipment, in order to enhance the level of service and transport efficiency.

From the perspective of the pattern of manifestation, the percentage of light-weighted and high added-value cargo will rise, and the demand of express delivery will increase largely. Along with the adjustment and upgrade of the industry structure of "Made in China 2025", future percentage of heavy chemistry products would gradually decrease, while the percentage of common consumptions, light 
weighted and high added value cargo would improve constantly. In addition, the industry will have higher level of requirements to provide safer, timelier and quicker transport service. In the meanwhile, with the upgrade of consumption and the development of e-commerce, the demand of express delivery cargo will obviously grow, which requires the organization and equipment to be more professional and efficient.

\section{References}

[1] Liancheng Li. How Many Railways and Roads China Needs? [M]. Beijing: China Planning Press, 2015, 7: 102-124.

[2] Dongqi Chen et al. Research on Major Changes of China's Medium and Long Term Economic Development [M]. Beijing: China Planning Press, 2013, 8: 35-38.

[3] Jisong Wu. The Top-level Design, Roadmap and Timetable of the New Urbanization [M]. Beijing: Beihang University Press, 2013, 4: 22-24.

[4] Derong Wang, Liang Cheng. Research on the Future Transportation Demand Forecast of China's Transportation [M]. Beijing: China Market Press, 2014, 8: 44-62

[5] Hualong Yang, Jinxiang Jian. Analysis on Adjustment of Transportation Structure in China [J]. Journal of Transportation Systems Engineering and Information Technology, 2002, 2: 11-13. 